\title{
Floral bud distortion in soybean and incidence in Central India
}

\author{
Jadhav Pravin $V^{1 *}$, Mane $S S^{2}$, Nandanwar $\mathrm{RS}^{3}$, Kale PB ${ }^{1}$, Dudhare $\mathrm{MS}^{1}$, Moharil MP ${ }^{1}$ \\ \& Dani $R^{1}$
}

1 Biotechnology Centre, Department of Agricultural Botany, Dr. Panjabrao Deshmukh Krishi Vidyapeeth, Akola, MS, India- 444104

2 Department of Plant Pathology, Dr. Panjabrao Deshmukh Krishi Vidyapeeth, Akola, MS, India- 444104

3 Department of Agricultural Botany, Dr. Panjabrao Deshmukh Krishi Vidyapeeth, Akola, MS, India- 444104

\begin{abstract}
We describe a peculiar and often harmful budding disorder in soybean, leading to huge yield loss in India. To determine the prevalence of floral distortion in soybean, an extensive random roving survey was undertaken in the soybean-growing regions of Madhya Pradesh, Maharashtra and the adjoining part of Karnataka states during two successive seasons of kharif (monsoon-planted) crops - Oct 2010 and Sept 2011. The average rate of the disorder ranged from $8.0 \%$ to $14.6 \%$ and severity from 2.0 to $90.0 \%$ during 2010 and 2011, respectively. Affected plants were found to have either no or deformed pods and distorted flowers, and they remained green after maturity. All the soybean varieties grown in the surveyed region (i.e. JS 335, JS 93-05, JS 73-23, JS 95-60, AMS-MB-5-19, CO-2, Bragg, JS 10-44, Samrat) were affected by the disorder. The PCR-based diagnosis revealed the absence of phytoplasma in symptomatic soybean samples.
\end{abstract}

Keywords: Glycine max, chlorosis, green stem, thickening and twisting stem, yield loss.

\section{Introduction}

Soybean [Glycine $\max (\mathrm{L})$.$] has attained vital status in Indian agriculture and oil economy.$ Maharashtra is the leading state after Madhya Pradesh in production of soybean, accounting for $13 \%$ of India's total soybean production (Anonymous, 2011). The area under soybean has increased from 300,000 ha (1970) to $10,327,000$ ha (2011) in India, but yield stagnation is the major concern in spite of its high potential. Although soybean has maintained a good showing among crops in the states, its potential to generate more revenue is being challenged by various abiotic and biotic stresses, including a number of diseases caused by viruses, bacteria, phytoplasmas, fungi and nematodes. More than 100 pathogens including five phytoplasmas cause disease in soybean. These phytopathogens are associated with plant diseases that contribute to significant crop losses worldwide, and occur on various crops in India, such as pigeon pea, chili, coconut, Indian fig, potato and sugarcane rather than soybean, causing 10-80 per cent yield losses (Khan \& Raj 2006, Raj et al. 2006).

In recent years soybean has been devastated by an unknown floral bud distortion. The symptoms produced did not resemble any of the documented disorders of soybean and were inconsistent in their distribution across locations. The research community has no information about its cause or control. Farmers only can explain the symptoms and distinguish symptomatic plants via various local names. The disorder is an emerging limiting factor for soybean production in India, particularly in central India. Despite an increase in published reports and evidence of losses, most researchers, extension workers and farmers remain unfamiliar with the disorder. Low familiarity with symptoms and feeble diagnostic facilities (or access to them) hampers detection and effective control in many countries. Molecular techniques are expensive and materials tricky to get hold of, although free diagnosis may be available outside the region. Effective treatment depends on cultural management and use of clean planting material; coordinating responses at a regional or national scale is difficult in countries where farmers are inadequately connected to national plant protection organizations. Greater awareness of the disorder is essential, beginning with wider knowledge of the

* Author for correspondence: tel +919423520822 Fax +917242258239 email : jpraveen26@yahoo.co.in 
symptoms and diagnostic support. This paper reports the incidence of the floral bud distortion in the major soybean growing regions of Madhya Pradesh, Maharashtra and Karnataka states of India.

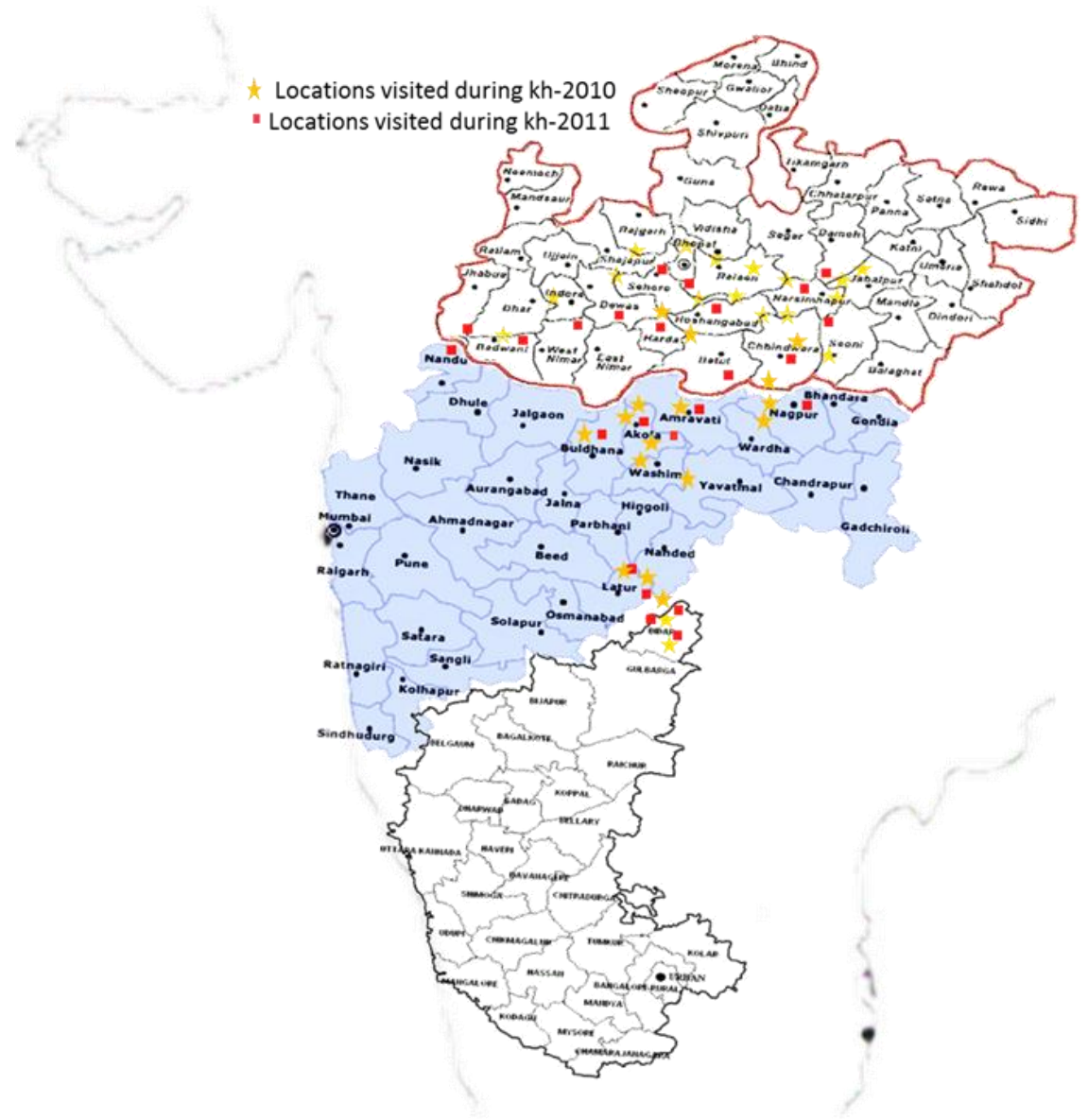

Figure 1: Map of Madhya Pradesh, Maharashtra and Karnataka states of India showing locations visited during two succeeding soybean growing seasons

\section{Materials \& Methods}

The comprehensive random roving survey was conducted to estimate the incidence of floral bud distortion in the major soybean growing areas of Madhya Pradesh, Maharashtra and adjoining parts of Karnataka state i.e. Bhopal, Hoshangabad, Indore, Jabalpur, Narsimhapur, Raisen, Seoni, Shajpur, Khandwa, Pipriya, Burhanpur, Pandana, Harsud, Khirkiya, Chindwara regions of Madhya Pradesh; Akola, Buldhana, Nandura, Amravati, Murtijapur, Udgir, Latur, Nagpur and Yavatmal regions of Maharashtra and Bhalki and Bidar district of Karnataka state (Fig. 1). The survey was done at R7-R8 ${ }^{\text {th }}$ crop stage, 65-70 days after sowing. During the survey, fields were visited randomly and for each field, 20 rows were randomly selected and plants along a 6-10-metre length of a row examined for typical signs of the disorder. Observations were taken from 41 fields on the incidence and severity of the disorder. The percentage of plants with the disorder was calculated from the plants counted in the $6-10 \mathrm{~m}$ samples of 20 rows. For the collection of affected samples, 2-4 plants per area along with asymptomatic plants were collected from all the fields visited. All collected plant samples were individually placed in plastic bags, tagged and transported in an ice chest. A total of 178 
samples were collected each year for two successive years for the kharif (wet-season) crop in October 2010 and September 2011.

The data were recorded for two successive seasons on the percent incidence of the disorder, losses in terms of pod set failure, the distribution of incidence across varieties and the morphology of symptoms at field level. Suspecting the cause to be a phytoplasma, PCR-based diagnosis of symptomatic plants was carried out using universal primers (P1-P7/P3-P7). The polymerase chain reaction (PCR) was performed in an Authorized Thermal Cycler (Eppendorff AG, Hamburg, Germany). Reactant concentrations were as previously described by Lee et al. (2002). Reaction conditions were as follows: $2 \mathrm{~min}$ at $94^{\circ} \mathrm{C}, 1$ cycle; $1 \mathrm{~min}$ at $94^{\circ} \mathrm{C}, 2 \mathrm{~min}$ at 52- $60^{\circ} \mathrm{C}, 3$ min at $72^{\circ} \mathrm{C}, 35$ cycles; and $10 \mathrm{~min}$ at $72^{\circ} \mathrm{C}, 1$ cycle.

\section{Results}

In the field, affected soybean plants showed a complex set of symptoms with the floral bud distortion. The disorder mainly affects flower development and leads to either no or deformed buds and pods. It shows proliferation at floral bud followed by prolonged vegetative phase with dark or yellow-green leaves in severely affected plants at early stages. Plants affected in later growth stages show failure in pod set, and only infrequently develop pods that can produce soybeans. Another virus-like conspicuous symptom was the chlorosis and necrosis of deformed leaves, and a few plants showed thickening and twisting of stems. The leaves of symptomatic plants were deformed (cup-like in appearance), dark green in colour and reduced in size ('little leaf'). The floral bud distortion exhibited decreasing apical dominance and distorted floral organs i.e. petals, stamens, carpel and ovary, leading to failure of pod development on affected plants. Similarly, pollen grain fertility tests revealed a number of sterile pollen grains in symptomatic plants (Fig. 2).

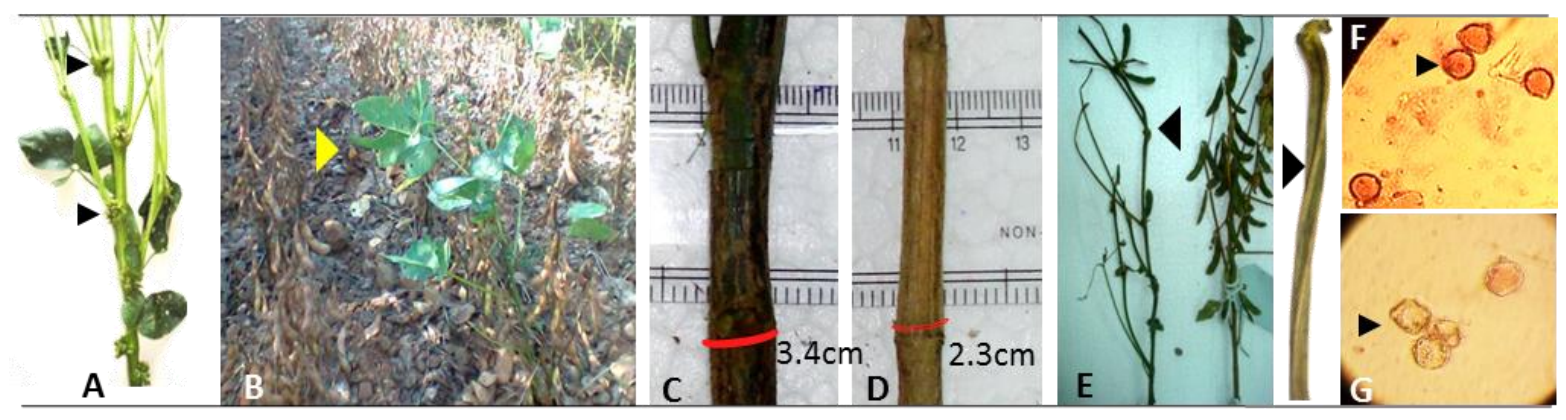

Figure 2: Symptoms of floral bud distortion in symptomatic soybean plant A: Symptomatic and asymptomatic soybean plant without pods; B: Green staying symptomatic soybean plant at maturity stage; C \& D: Thicken stem of symptomatic plant (C) and asymptomatic plant with normal stem (D)at maturity stage; E : Twisting of stem in symptomatic plant; F:Stained pollen (fertile) in asymptomatic plant; G: Sterile pollens in symptomatic plants 
Table 1: Incidence of floral bud distortion of soybean in Madhya Pradesh, Maharashtra and Karnataka during the kharif (wet-season) in 2010 and 2011

\begin{tabular}{|c|c|c|c|c|c|c|c|c|c|c|c|c|c|c|c|c|c|c|c|}
\hline \multirow[b]{4}{*}{ SN } & \multirow[b]{4}{*}{ Soybean genotypes } & \multicolumn{18}{|c|}{ Prevalence of Floral bud distortion (\%) } \\
\hline & & \multicolumn{6}{|c|}{ Madhya Pradesh } & \multicolumn{6}{|c|}{ Maharashtra } & \multicolumn{6}{|c|}{ Karnataka } \\
\hline & & \multicolumn{2}{|c|}{ Min } & \multicolumn{2}{|c|}{$\operatorname{Max}$} & \multicolumn{2}{|c|}{ Mean } & \multicolumn{2}{|c|}{ Min } & \multicolumn{2}{|c|}{ Max } & \multicolumn{2}{|c|}{ Mean } & \multicolumn{2}{|c|}{ Min } & \multicolumn{2}{|c|}{ Max } & \multicolumn{2}{|c|}{ Mean } \\
\hline & & Kh-10 & Kh-11 & Kh-10 & Kh-11 & Kh-10 & Kh-11 & Kh-10 & $K h-11$ & Kh-10 & $K h-11$ & Kh-10 & Kh-11 & Kh-10 & Kh-11 & Kh-10 & Kh-11 & Kh-10 & Kh-11 \\
\hline 1 & Co-2 & 4.0 & - & 50.0 & - & $\begin{array}{c}17.3 \\
(\mathrm{~L}-4 / 32 \mathrm{ac})\end{array}$ & - & - & - & - & - & - & - & - & & - & - & - & - \\
\hline 2 & JS 93-05 & 5.0 & 5.0 & 80.0 & 30.0 & $\begin{array}{c}24.8 \\
\text { (L-10/58ac) }\end{array}$ & $\begin{array}{r}13.6 \\
\text { (L-11/56.5ac) }\end{array}$ & - & - & - & - & - & - & - & & - & - & - & - \\
\hline 3 & JS $73-23$ & 5.0 & - & 5.0 & - & $\begin{array}{c}5.0 \\
(\mathrm{~L}-2 / 14 \mathrm{ac})\end{array}$ & - & - & - & - & - & - & - & - & & - & - & - & - \\
\hline 4 & JS 95-60 & 5.0 & - & 10.0 & - & $\begin{array}{c}7.5 \\
\text { (L-2/30 ac) }\end{array}$ & - & - & - & - & - & - & - & - & & - & - & - & - \\
\hline 5 & JS $10-44$ & 15.0 & 5.0 & 15.0 & 20.0 & $\begin{array}{c}15.0 \\
(\mathrm{~L}-1 / 2 \mathrm{ac})\end{array}$ & $\begin{array}{c}16.3 \\
\text { (L-4/19ac) }\end{array}$ & - & - & - & - & - & - & - & & - & - & - & - \\
\hline 6 & Sonia Gold & 10.0 & - & 10.0 & - & $\begin{array}{c}10.0 \\
(\mathrm{~L}-2 / 14 \mathrm{ac})\end{array}$ & - & 15.0 & - & 15.0 & - & $\begin{array}{c}15.0 \\
(\mathrm{~L}-3 / 35 \mathrm{ac})\end{array}$ & - & 15.0 & & 20.0 & - & $\begin{array}{c}17.5 \\
(\mathrm{~L}-3 / 35 \mathrm{ac})\end{array}$ & - \\
\hline 7 & JS 335 & 5.0 & 5.0 & 5.0 & 80.0 & $\begin{array}{c}5.0 \\
(\mathrm{~L}-1 / 2 \mathrm{ac})\end{array}$ & $\begin{array}{c}21.0 \\
(\mathrm{~L}-5 / 23 \mathrm{ac})\end{array}$ & 5.0 & 2.0 & 20.0 & 90.0 & $\begin{array}{c}12.5 \\
\text { (L-6/52ac) }\end{array}$ & $\begin{array}{c}11.6 \\
(\mathrm{~L}-15 / 66 \mathrm{ac})\end{array}$ & 15.0 & 4.0 & 15.0 & 8.0 & $\begin{array}{c}12.5 \\
(\mathrm{~L}-1 / 13 \mathrm{ac})\end{array}$ & $\begin{array}{c}7.5 \\
\text { (L-3/17ac) }\end{array}$ \\
\hline 8 & AMS-MB-5-19 & - & - & - & - & - & - & 5.0 & - & 5.0 & - & $\begin{array}{l}5.0 \\
(\mathrm{~L}-1)\end{array}$ & - & - & & - & - & - & - \\
\hline 10 & Bragg & - & - & - & - & - & - & 5.0 & - & 5.0 & - & $\begin{array}{l}5.0 \\
(\mathrm{~L}-1)\end{array}$ & - & - & & - & - & - & - \\
\hline 11 & Samrat & - & - & - & 30.0 & - & $\begin{array}{c}30.0 \\
\text { (L-1/7.5ac) }\end{array}$ & - & - & - & - & - & - & - & - & - & - & - & - \\
\hline 12 & NRC- 37 & - & - & - & - & - & - & - & - & - & 2.0 & $\begin{array}{l}2.0 \\
(\mathrm{~L}-1)\end{array}$ & - & - & - & - & - & - & - \\
\hline 13 & JS 94-52 & - & - & - & 10.0 & - & $\begin{array}{c}10 \\
(13 \mathrm{ac})\end{array}$ & - & - & - & - & - & - & - & - & - & - & - & - \\
\hline
\end{tabular}

Note: (*) soybean genotypes/breeding material under experimental plots; (-) not available; L- number of places/locations; ac: area in acres 
The average disease incidence ranged from 8.0 to $14.6 \%$ in different parts of the states surveyed. During kharif 2010, the highest incidence of up to $80 \%$ was noticed in fields of the villages of Simriya and Karakbail in the Narsimhapur district of Madhya Pradesh. However, during kharif 2011, the entire field was severely distorted in the village of Hadgaon $(>80 \%)$ in the Akola district of Maharashtra, and incidence was also high in Borgaon Bujrug village $(>50 \%)$ of the Pandana Tahasil district of Madhya Pradesh. In Karnataka state, the incidence of the disorder was found to be $8.0-14.5 \%$ for all varieties during both the seasons.

The incidence was observed irrespective of soybean variety in all regions surveyed. During kharif 2010, the highest incidence was observed on genotype JS 93-05 (80\%) grown in Madhya Pradesh, followed by CO-2 (50\%). However, the following year the highest incidence was recorded in genotype JS 335 (90\%), followed by JS 93-05 (58.8\%) (Fig. 3). Values for the mean, minima and maxima are provided for all varieties in Table 1.

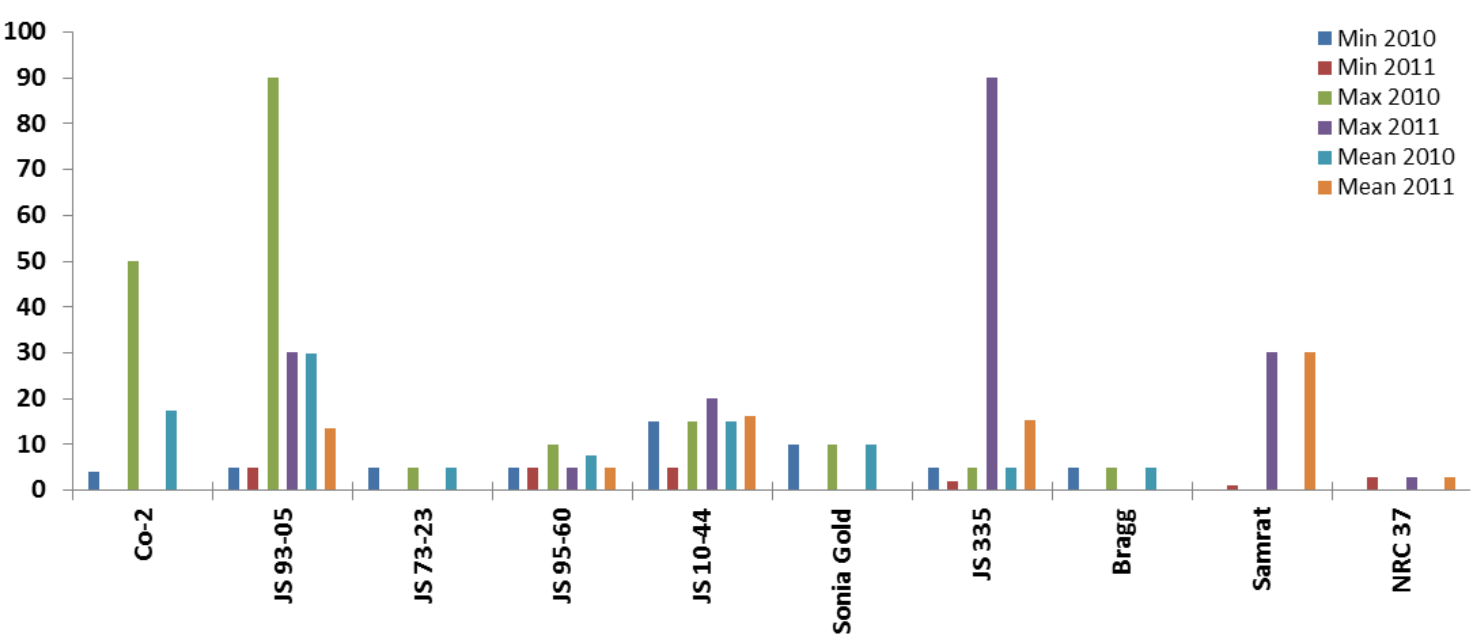

Figure 3: Incidence of Floral bud distortion in soybean genotypes during Kharif 2010 and 2011 under surveyed region

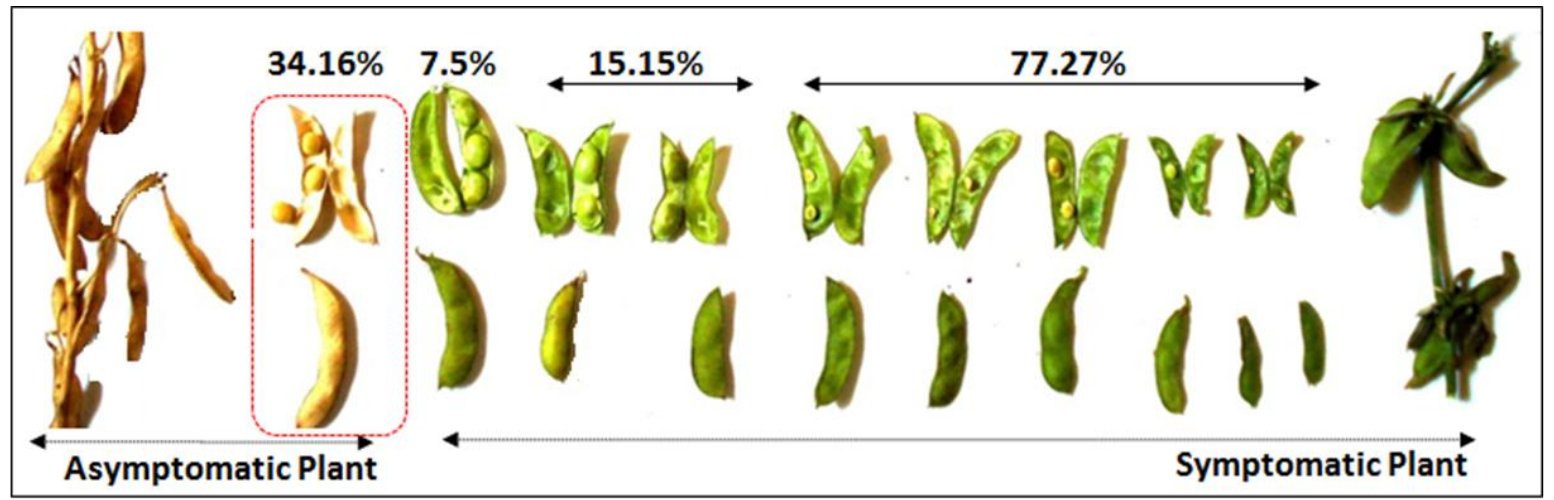

Figure 4: Percent number of pods in symptomatic (affected by FBD) and asymptomatic soybean plants

Yield levels are lowered due to the disorder through reducing pod set and seed formation in affected plants. Fig. 4 shows the differences in percent of pod formation of symptomatic and asymptomatic soybean plants from the same field. Pod formation can occur in plants affected at later growth stages. The replicated data reveals the severe effect of the disorder on flower development. Asymptomatic plants produced a large minority of threeseeded pods $(34.2 \%)$, a majority $(54.5 \%)$ of two-seeded pods and only $9.2 \%$ of single-seeded pods. In contrast, a symptomatic plant produced either no pods at all, or a highly reduced 
number, i.e. $7.5 \%$ of three-seeded pods, $15.2 \%$ of two-seeded and $8.3 \%$ of single-seeded pods. Asymptomatic plants produced very few sterile pods per plant (almost 2.2\%), but symptomatic plants had $77.3 \%$ sterile pods per plant, the main cause of severe yield losses.

On the basis of morphological symptoms of floral bud distortion, PCR-based diagnosis was carried out to test whether phytoplasma was the causal agent of the disorder. The PCR reaction showed an amplicon of $1.1 \mathrm{~kb}$ size from samples of sugarcane grassy shoot known to be infected with phytoplasma. However, there was no such amplicon found in 29 test samples of symptomatic soybean plants.

\section{Discussion}

Soybean has been facing a serious set-back due to the exceptional occurrence of this disorder over the past decade in central India. Attempts to understand the symptoms and the causal agent have been limited because of lack of awareness of the disorder and because of popular publications. Farmers explain the symptoms and recognize plants in different local names, such as 'Banzwa/ Rogi poudha', 'Vanz pata' or 'Butti Poudha', indicating unproductive, stunted (in some cases) soybean plants without pods. Exceptionally, similar symptoms have been observed in another crop (mungbean at Gotegaon, Madhya Pradesh) growing in a neighbouring field, perhaps because of increasing occurrence as well as an extended host range of the causal agent.

Morphological characterization of collected symptomatic samples was carried out here to understand the basis of the large economic losses in soybean. Earlier findings revealed that losses are greatest when young plants are affected, or when affected seeds are sown. In such cases it can be assumed that floral bud distortion might result from early infection and reduced pod setting from late-stage infections of causal agent. Both bud proliferation and reduced pod set minimizes yield on symptomatic plants.

Anecdotal and photographic evidence suggest a range of potential causes of the floral bud distortion, including an unknown pathogen, insect damage and soil or environmental stresses involving viruses. Greater awareness of the disorder is needed to widen knowledge of the symptoms and to improve diagnostic support. Critical diagnosis of the cause(s) and the development of an effective management strategy to minimize yield losses is the next step.

\section{Acknowledgements}

The present investigation was supported by Dr. Panjabrao Deshmukh Krishi Vidyapeeth, Akola, Maharashtra State, India.

\section{References}

Anonymous (2011) Soybean. http//www.asasoya.org

Khan MS \& Raj SK (2006) First report of molecular detection of an Aster yellows phytoplasma isolate infecting chilli (Capsicum annuum) in India. Plant Pathology 55: 822

Raj SK, Khan MS, Snehi SK, Srivastava S \& Singh HB (2006) 'Candidatus phytoplasma asteris' isolate associated with a little leaf disease of pigeonpea in India. Plant Pathology 55:823

Lee ME, Grau CR, Lukaesko LA \& Lee M (2002) Identification of aster yellows phytoplasma in soybean in Wisconsin based on RFLP analysis of PCR-amplified products (16S rDNAs). Canadian Journal of Plant Pathology 24: 125-130 


\section{الملخص العربي}

تشوه البر اعم الزهرية فى فول الصويا فى وسط الهند

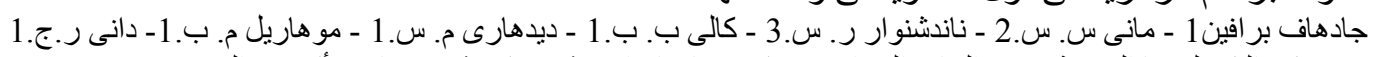

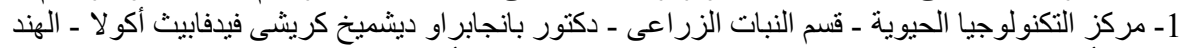

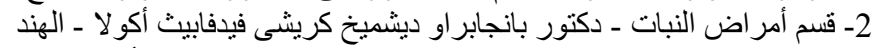

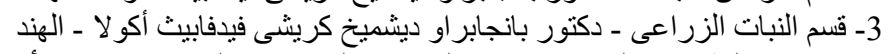

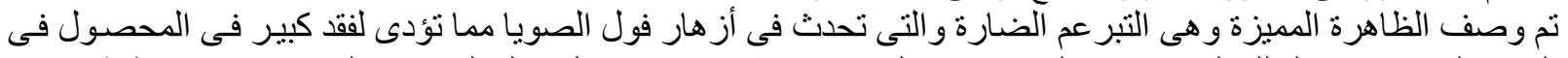

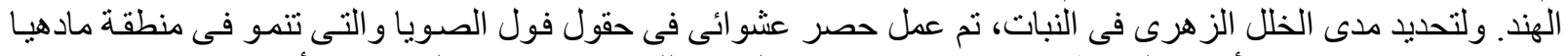

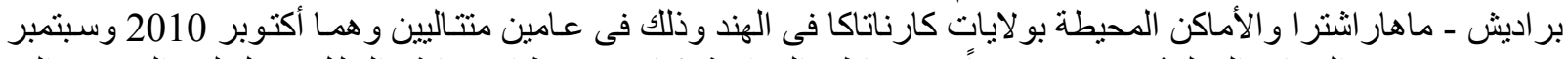

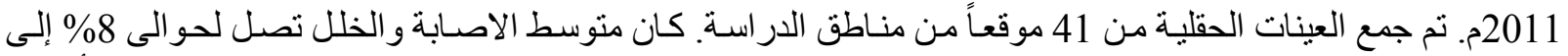

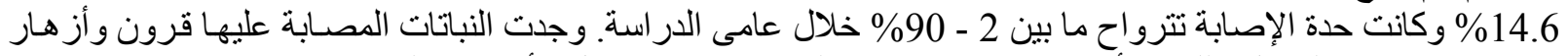
i.e. JS : مشو هة و احتفظت الحقول باللون الأخضر بعد النتهاء فترة النضوج. 335, JS 93-05, JS 73-23, JS 95-60, AMS-MB-5-19, CO-2, Bragg, JS 10-44 مصابة ومشو هة. أوضحت الدراسة الور اثية باستخدام تقنية "بى سى أر" غياب الفيتوبلازما فى عينات الفول. 